\title{
Travel Times of Seismic Sea Waves to Honolulu
}

\author{
Bernard D. ZetLER ${ }^{1}$
}

THE SEISMIC SEA WAVE which struck the Hawaiian Islands on April 1, 1946, has again focused attention on the necessity for adequate protective measures against similar disasters in the future. The problem is obviously complex, involving rapid location of the epicenter, the detection of the sea wave as it moves toward the Hawaiian Islands, a quick method of determining the time the wave will reach the islands, and finally an adequate means of providing security for people and property. The purpose of this study was the preparation of a chart of the Pacific Ocean which would show the travel time to Honolulu of a seismic sea wave from the plotted position of an earthquake epicenter (see Fig. 1, insert sheet). Given the time of the disturbance, the arrival time of the wave at Honolulu becomes immediately available.

Oceanographers have long accepted the concept that the velocity of a seismic sea wave is a function of the depth of water and they have expressed it mathematically as $v=\sqrt{ } g d$, where $v$ is the velocity of the wave, $g$ the acceleration of gravity, and $d$ the depth of the water. However, this formula for velocity has been considered by some authorities to be a rough approximation; it was believed that the actual velocity would always be somewhat slower.

The results of the computations made in the course of the study by Green (1946) created more confidence in the accuracy of travel times computed by means of this formula. These computations were not influenced by the recorded arrival times; the times to several of the more distant places

\footnotetext{
${ }^{1}$ Mathematician, U. S. Coast and Geodetic Survey, Washington, D. C. Manuscript received March 17, 1947.
}

were computed before it was known that the sea wave had been recorded on the gages. Table 1 of that report lists 12 places whose distances from the epicenter vary from 1,610 to 8,066 statute miles. A comparison of observed with computed travel times to these places shows an average variation of 1.2 per cent, which is not consistently in one direction.

It was decided that the procedures used in the above project could be adopted in the preparation of a chart which would show the travel time of any seismic sea wave to Honolulu. A series of $1 / 2$-hour curves would be drawn on the chart such that each would represent the length of time a sea wave would take to reach Honolulu from an epicenter at any point on the curve.

Points to be used as epicenters of sea waves were selected in various directions from Honolulu, and travel times were computed, using soundings from large-scale charts, along arcs of great circles between these points and Honolulu. Half-hour intervals were plotted along each arc with numerical time values increasing with distance from Honolulu. The time curves were drawn by connecting the respective $1 / 2$-hour points.

Although observed travel times were available for a number of sea waves which had previously been recorded on the Honolulu tide gage, it was considered desirable to use computed rather than observed data in the construction of the chart. However, the positions of the epicenters of recorded waves were included among the points from which travel times were computed in order to make available a comparison of observed and computed travel times (see Table 1).

In preparing the time data along any particular path, a great circle course between 
the epicenter and the entrance to Honolulu Harbor was plotted on a chart of the Pacific Ocean. The path was transferred to larger scale nautical charts and then divided into sections of 120 nautical miles each, except when rapid changes in depth required sections of shorter length. The average depth in each section was taken and the time required to pass over it was computed as follows:

Let $d$ represent the mean depth, in fathoms, of the 120-mile section and $t$ the travel time of the sea wave over that section.

Since $v=\vee g d=8.23 \vee V d$ nautical miles per hour, $t=120 / 8.23 \quad \vee d=14.58 / \sqrt{ } d$ hours.

The times thus computed were added cumulatively, increasing with distance from Honolulu, and the $1 / 2$-hour points were determined by interpolation.

The dividing of a path into small sections increases the precision of the determinations over those which are obtained by using a mean depth over a whole distance. The 120mile points were usually 0.25 to 0.35 hour apart, thus allowing for reliable interpolation of $1 / 2$-hour points which would have been impossible were the path to be considered as a whole.

When a great circle course for a seismic sea wave is first laid off on large-scale charts, there are several details to be considered. If the path crosses a large unit of land, the portion of the wave front which reaches Honolulu will have to go around that land. Because the part of the wave front in deeper water will advance more rapidly, the path is considered the combination of arcs of two great circles joined in the deep water off the coast. If the path of a wave involves crossing a large section of shoal water, then the time of the wave front which diverges somewhat from the great circle course, but which travels over a deeper course, must be considered. An excellent example of the latter was found in the com- putation of the travel time of the wave from the Aleutian Trench on April 1, 1946, to Sitka, Alaska. The travel time along a great circle course, through shoal water most of the way, was computed as about 7 hours. By considering a path going to the southeast for about 90 miles and then moving along a great circle course from that point to Sitka, the time was calculated to be about 3 hours, which was in almost perfect agreement with the observed time.

The latter example is an extreme case. More frequently there was found a condition in which part of a great circle course covered an area less deep than that covered by an adjacent path. Despite the additional distance covered in diverging from a great circle course to get into deeper water, the total travel time may be less than that along the original great circle path. Shallow areas of this type caused irregularities in the time curves and necessitated the computation of additional paths and the consideration of the bathymetric pattern.

The problem of how to treat the computation of the travel time of a wave whose path lies in a deep channel with comparatively shallow water on both sides is a troublesome one. If the formula were followed rigorously in such a case, the front of the wave would gradually have to become more and more pointed as the wave moved forward, the shallow water on either side slowing down that portion of the wave front passing over it. The concept of such a pointed wave front did not seem reasonable, and the velocity was computed as just slightly faster than that over the shallow area. The observed travel times from several epicenters lying in deep channels were, found to compare favorably with the times thus computed.

Some of the epicenters used in comparing observed with computed travel times were found to plot on land near ocean deeps. There have been some differences of opinion among seismologists whether the true epi- 
central positions are on or off shore. The method used in this study necessitated a given depth of water to make a computation possible, and therefore the times were computed to the ocean deeps which are near the plotted epicenters. The comparison of observed and computed travel times would seem to indicate that this procedure is reasonable.

Three seismic sea waves which originated near the Japanese island of Honshu have been recorded on the tide record at Honolulu. The observed travel times exceed the computed times by 14, 23, and 49 minutes. The first two differences are sizable but not necessarily serious. There are several factors which can contribute to a small consistent variation. Accurate computations of travel time require adequate and reliable soundings. Some areas in the Pacific are inadequately surveyed, and the accuracy of some soundings in other areas is questionable. For the 120-mile travel path sections which contain large variations in depth, the procedure was to use a mean depth after rejecting occasional extremely $\mathrm{sh}$ a $11 \mathrm{ow}$ depths. This technique and the resulting mean depths are somewhat subjective and could lead to small inaccuracies in travel time.

The seismic disturbance off the south coast of Honshu on December 7, 1944, created a sea wave which arrived at Honolulu 9 hours and 9 minutes later; whereas the computed travel time for the path is 8 hours and 20 minutes. The epicenter of the December 20, 1946 , sea wave is approximately 170 nautical miles west of the 1944 epicenter, the water between the two is relatively shallow, and great circle paths from the two to Honolulu would virtually coincide. The difference of only 3 minutes between the observed travel times cannot be explained by some of the difficulties mentioned above. It seems probable that some of the 49-minute difference must be attributed to tide gage operation, tide record interpretation, the seismological determination of epicenter, or a combination of these factors.

A serious misinterpretation of a tide marigram can take place if the waves are small in amplitude. The first wave is usually smaller than those immediately following it and may not be recognizable because of the seiche. Therefore a time of arrival which appears to be definite may refer to the second wave rather than the first. With an observed travel time greater than its true value, the time difference, computed minus observed, is large negatively.

Besides giving the travel time of a seismic sea wave from an epicenter, the chart may also be used in conjunction with apparatus which detects the sea wave as it moves toward the Hawaiian Islands. Midway Island, for example, lies approximately on a great circle arc between Honshu and Honolulu. If a wave were received at Midway from an epicenter near Honshu, a warning could be sent to Honolulu. The travel time difference between Midway and Honolulu of about 2 hours and 50 minutes is readily obtained from the chart. The necessary condition for using the chart in this fashion is that the outpost lie close to the great circle course from the epicenter to Honolulu. There are a number of other islands in the Pacific Ocean whose positions make possible their use as detector outposts for waves from other directions.

Travel time to other places in the $\mathrm{Ha}$ waiian Islands can be estimated with the aid of the time curves near the islands. For example, a seismic sea wave originating near Chile would reach Hilo about a half-hour before it reached Honolulu, but a sea wave from southeast Alaska would arrive at both places at approximately the same time.

Table 1 gives the geographic position of epicenter, the Greenwich time of the seismic disturbance, the location of the gage which recorded the receipt of the seismic sea wave 
TABLE 1

Comparison of Observed and Computed Travel Times of Seismic Sea Waves

(Mean variation of computed travel times with respect to observed times $=2.3$ per cent.)

\begin{tabular}{|c|c|c|c|c|c|c|c|c|c|}
\hline \multicolumn{7}{|c|}{ EARTKQUAKE } & \multirow{3}{*}{$\begin{array}{c}\text { LOCATION } \\
\text { OF } \\
\text { TIDE GAGE }\end{array}$} & \multirow{3}{*}{$\begin{array}{c}\text { OBSERVED } \\
\text { TRAVEL } \\
\text { TIME }\end{array}$} & \multirow{3}{*}{$\begin{array}{c}\text { TIME } \\
\text { DIFFERENCE } \\
\text { (COMPUTED } \\
\text { MINUS } \\
\text { OBSERVED) }\end{array}$} \\
\hline \multicolumn{3}{|c|}{ Epicenter } & \multicolumn{4}{|c|}{ Greenwich Time } & & & \\
\hline Near & Lat. & Long. & Year & Month & Day & Hour & & & \\
\hline & deg. & deg. & 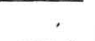 & & & h. m. & & h. $\mathrm{m}$. & $\min$. \\
\hline Colombia & $1 \mathrm{~N}$. & 80 W. & 1906 & Jan. & 31 & 1533 & Honolulu & 1257 & -27 \\
\hline Chile & 33 S. & $72 \mathrm{~W}$. & 1906 & Aug. & 17 & 0041 & Honolulu & 1512 & -2 \\
\hline Kermadec Is. & $29.2 \mathrm{~S}$ & $177.0 \mathrm{~W}$. & 1917 & May & 1 & 1827 & Honolulu & 801 & -6 \\
\hline Kuril Is. & $46.5 \mathrm{~N}$. & $151.4 \mathrm{E}$. & 1918 & Sept. & 7 & 1716 & Honolulu & 636 & +4 \\
\hline Tonga Is. & 21.2 S. & $172.5 \mathrm{~W}$. & 1919 & April & 30 & $07 \quad 17$ & Honolulu & 636 & -4 \\
\hline Chile & $29.0 \mathrm{~S}$. & $71.0 \mathrm{~W}$. & 1922 & Nov. & 11 & 0432 & Honolulu & 1458 & +2 \\
\hline Kamchatka & $54.0 \mathrm{~N}$. & $161.0 \mathrm{E}$. & 1923 & Feb. & 3 & 1602 & Honolulu & 618 & +6 \\
\hline Kamchatka & $55.7 \mathrm{~N}$ & $162.5 \mathrm{E}$. & 1923 & April & 13 & 1531 & Honolulu & 644 & -8 \\
\hline California & $34.9 \mathrm{~N}$. & $121.0 \mathrm{~W}$. & 1927 & Nov. & 4 & 1351 & Hilo & 508 & $-3 *$ \\
\hline Mexico & $16.2 \mathrm{~N}$. & $97.2 \mathrm{~W}$. & 1928 & June & 17 & 0319 & Hilo & 830 & $0 *$ \\
\hline Aleutian Is. & $51 \mathrm{~N}$. & 170 W. & 1929 & Mar. & 7 & 0135 & Hilo & 445 & $-9 *$ \\
\hline Solomon Is. & $10.6 \mathrm{~S}$ & $161.7 \mathrm{E}$. & 1931 & Oct. & 3 & 1913 & Honolulu & 746 & -11 \\
\hline Solomon Is. & $10.6 \mathrm{~S}$ & $161.7 \mathrm{E}$. & 1931 & Oct. & 3 & 1913 & Hilo & 819 & $-29 *$ \\
\hline Mexico & $19.2 \mathrm{~N}$. & $104.2 \mathrm{~W}$. & 1932 & June & 3 & $\begin{array}{ll}10 & 37\end{array}$ & Honolulu & 742 & +13 \\
\hline Japan & $39.1 \mathrm{~N}$. & 144.7 E. & 1933 & Mar. & 2 & 1731 & Honolulu & 733 & $-14 \dagger$ \\
\hline Alaska & $55.5 \mathrm{~N}$. & $157.3 \mathrm{~W}$. & 1938 & Nov. & 10 & 2019 & Honolulu & 501 & -1 \\
\hline Chile & $31.5 \mathrm{~S}$. & $71.4 \mathrm{~W}$. & 1943 & April & 6 & 1607 & Honolulu & 1531 & -24 \\
\hline Japan & $33 \mathrm{~N}$. & 137 E. & 1944 & Dec. & 7 & 0436 & Honolulu & 909 & $-49 \dagger$ \\
\hline Aleutian Is. & $53.5 \mathrm{~N}$. & $163.0 \mathrm{~W}$. & 1946 & April & 1 & 1229 & Honolulu & 434 & -4 \\
\hline Japan & $33.5 \mathrm{~N}$. & $133.7 \mathrm{E}$. & 1946 & Dec. & 20 & 1919 & Honolulu & 932 & $-23 \dagger$ \\
\hline
\end{tabular}

* Computed times to Hilo were estimated with the aid of near-by time curves.

$\rightarrow$ See text for a discussion of these differences.

in the Hawaiian Islands, the observed travel time, and the difference between computed and observed travel times. The computed travel times to Hilo were estimated with the aid of near-by time curves. A number of other seismic sea waves have reached the Hawaiian Islands and the available marigrams were examined. These were not included in the table because the amplitudes, as recorded by the gages, were too small to permit the determination of the first rise or fall of the waves. The natural seiche condition at both Honolulu and Hilo was the primary reason for this difficulty.

\section{REFERENCES}

Bodle, R. R. Note on the earthquake and seismic sea wave of April 1, 1946. Amer. Geophys. Union Trans. 27: 464-465, 1946.

BRITISH AsSOCIATION FOR THE ADVANCEMENT of ScIENCE, Comn. on Seismol. Invest. Rpt. (through 1917); Internatl. Seismol. Sum. (from 1918).

Green, C. K. Seismic sea wave of April 1, 1946, as recorded on tide gages. Amer. Geophys. Union Trans. 27: 490-500, 1946.

Heck, N. H. List of seismic sea waves. Union Geodesique et Geophysique Internatl., Ann. Com. pour l'Etude des Raz de Marée, no. 4: 20-41, 1934.

InTERnational Seismological Summary. See BRITISH AsSOCiATION.

JAGGAR, T. A. The great tidal wave of 1946. Nat. Hist. 55: 263-268, 1946.

Macdonald, G. A., F. P. Shepard, and D. C. Cox. The tsunami of April 1, 1946, in the Hawaiian Islands. Pacific Sci. 1: 21-37, 1947.

Pownrs, H. A. The tidal wave of April 1, 1946. Volcano Letter (Honolulu), no. 491: 1-4, 1946.

United States Coast and Geodetic Survey. Manual of tide observations. iv +92 p., 1 pl. Spec. Pub. 196, Washington, D. C., 1941.

United States earthquakes, 1939. iii +69 p., 1 pl. Serial 637, Washington, D. C., 1941. United States earthquakes, 1943. iv +49 p., 2 pl. Serial 672, Washington, D. C., 1945. United States earthquakes, 1944. iv +43 p., 2 pl. Serial 682, Washington, D. C., 1946. 